\title{
PROPOSED APPROACH FOR IMPROVING RNA CRYPTO-KEY BASED ON POL YNOMial CONVOLUTION
}

\author{
Estabraq Abdulredaa Kadhim ${ }^{1}$ \\ ${ }^{1}$ Computer Engineering Techniques Department/AL-Israa University Collge/Baghdad/Iraq \\ Estabraq_ai 1989@yahoo.com
}

\begin{abstract}
Random Number Generators are fundamental tools for cryptography protocols and algorithms. The basic problems that face any crypto key generator are randomness, correlations and distribution of the state of key sequence. This paper proposed a new method to enhance RNA crypto key generation. It has been implemented by extending the crypto key by applying polynomial convolution technique which extracts the mask filter from the same RNA key sequence depending on the start and end codon properties. This will provide another high level of extension and generate random-strength crypto key. The proposal approach could pass through the statistical measurements successfully and achieved high rate of randomness (approximated to 96\%).
\end{abstract}

Keywords - Cryptography, Key generation, RNA, Bimolecular Computation, Polynomial $\underline{\text { Convolution. }}$

\section{INTRODUCTION}

Random numbers generations are _ major tools in many applications of cryptography such as key generation [1]. The security of cryptography methods basically _ depends on the robustness of encryption method and secrecy of key [3]. It is so important to provide generators which are capable to produce amount of secure random numbers such as polynomial

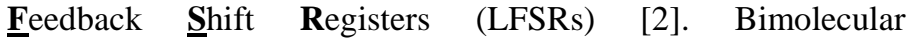
Computation Methods (BMC) have been developed for a various field of operations on DNA and RNA strands. BMC methods have _ solved hard combinatorial search problems such as Travelling Salesman Problem (TSP), breaking the Data Encryption Standard (DES) and for cryptography key generation [4].This approach will propose new method to improve RNA crypto key generation basically by depending on the concept of Polynomial convolution 1D, this technique will add second level of extension to achieve a desired level of secrecy and randomness In [5], A. Hassan proposed a method for key generation based on the concept of translating RNA to protein chain. Their approach first determines a key sequence size, for example 9 byte, then it produces crypto key with extended length suitable with the length of secret message. Their proposed approach consists of several steps contain (Mapping, Extended, Complementing and Rotation). The generated key was acceptable according to statistical tests of randomness.

\section{DNA AND RNA TRANSCRIPTION}

DNA is a double stranded sequence of four nucleotides; the four nucleotides that compose a strand of DNA are as follows:

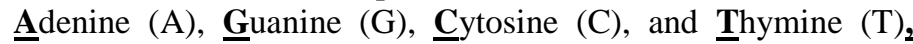
they are often called bases. The chemical structure of DNA (the famous double- helix) was discovered by James Watson and Francis Crick in 1953. It consists of a particular bond of two linear sequences of bases. This bond follows a property of complementarity: $\underline{A}$ denine bonds with $\underline{\text { Thymine }}(\mathrm{A}-\mathrm{T})$ and vice

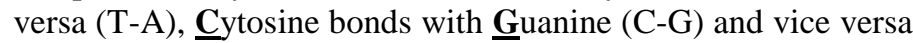
(G-C). This is known as Watson-Crick complementarity. Each DNA strand has two different ends that determine its polarity: the 3. 'end, and the 5. 'end. The double helix is an anti-parallel (two strands of opposite polarity) bonding of two complementary strands [6].

\section{RNA CRYPTOSYSTEM}

RNA-Crypto System (shortly RCS) is a private key algorithm to encrypt data, in particular from the observation of RNA behavior and some of its properties. The RNA sequences have some sections called Introns. Introns, derived from the term "intragenic regions", are non-coding sections of precursor mRNA (pre-mRNA) or other RNAs, that are removed (spliced out of the RNA) before the mature RNA is formed.

Once the introns have been spliced out of a pre-mRNA, the resulting mRNA sequence is ready to be translated into a protein. The corresponding parts of a gene are known as introns as well. It uses the presence of Introns in the RNA-Crypto System output as a strong method to access to the secret key to code the messages. In the RNA-Crypto System algorithm, the introns are sections of the ciphered message with non-coding information as well as in the precursor mRNA [7].

are Equipment, Middle-ware and Introduction [1]. Equipment is made up of sensors and actuators, the Middle-ware provides stockpiling and processing apparatuses and finally, the introduction provides the elucidation devices open on different steps. It is not plausible the processing of information that has been collected from a great number of sensors, which set mindful Middle-ware arrangements are suggested for enabling a sensor for choosing the most critical data to be handled [24]. 
Characteristically speaking, the design of the internet of things offers no suitable edge to achieve the fundamental actions

\section{Polynomial Vector Convolution}

In mathematics and some particular functional analysis, convolution is a mathematical operation on two functions $g$ and $\mathrm{f}$, to produce a third function that is typically showed as a modified version of one of the original two functions in which one of the original functions is translated. Convolution is similar to cross-correlation. It has many applications in probability, statistics, computer vision, image and signal processing [9]. Segment is made out of a four-round structure utilizing two nondirect substitution boxes S7 and S9. The structure is compacted in two rounds utilizing parallelism. The unequal division of FI is because of the way that objective elements of odd size are for the most part superior to those of even size from the perspective of provable security against direct and differential cryptanalysis. S7 and S9 have been planned in a way that stays away from direct structures in FI. This reality has been affirmed by measurable testing. S-boxes (S7 and S9) are actualized in combinational rationale despite the fact that they could be executed by "look-into tables" to diminish the extent of our usage. As a result of the parallelism, just two part of each S7 and S9 is required for the calculation of A5. Along these lines we utilize each S7 and S9 part 120 times.

Let $\mathrm{m}=$ length $(\mathrm{u})$ and $\mathrm{n}=$ length $(\mathrm{v})$. Then $\mathrm{w}$ is the vectors of length $\mathrm{m}+\mathrm{n}-1$ whose kth element is:

$W(k)=\sum_{j} u(j) v(k-j+1)$

The sum is over all the values of $\mathrm{j}$ that lead to legal subscripts for $\mathrm{u}(\mathrm{j})$ and $\mathrm{v}(\mathrm{k}-\mathrm{j}+1)$, specifically $\mathrm{j}=\max (1, \mathrm{k}+1-\mathrm{n}): 1: \min (\mathrm{k}, \mathrm{m})$. When $\mathrm{m}=\mathrm{n}$, this gives

$\mathrm{w}_{1}=\mathrm{u}_{1} * \mathrm{v}_{1}$

$\mathrm{w}_{2}=\mathrm{u}_{1} * \mathrm{v}_{2}+\mathrm{u}_{2} * \mathrm{v}_{1}$

$\mathrm{w}_{3}=\mathrm{u}_{1} * \mathrm{v}_{3}+\mathrm{u}_{2} * \mathrm{v}_{2}+\mathrm{u}_{3} * \mathrm{v}_{1}$

$\mathrm{w}_{\mathrm{n}}=\mathrm{u}_{1} * \mathrm{v}_{\mathrm{n}}+\mathrm{u}_{2} * \mathrm{v}_{\mathrm{n}-1}+\ldots+\mathrm{u}_{\mathrm{n}} * \mathrm{v}_{1}$

\section{IMPROVEMENT OF RNA-CRYPTO-KEY}

This approach discusses some drawbacks that have been observed by using the previous approach of RNA key generation, and we try to find an improved version for addressing those mistakes stated as follows:

- Translation of mRNA strand based on start and end codons, investigated from which by calculating the number of these confined codons to apply rotate shift on RNA sequence.

Benefit from mRNA translation just for applies "Rotate Shift on RNA sequence "may be considered as weakness investment for this property, it looks like "simple permutation".

In this approach, extended RNA-Crypto-key basically depends on the "Polynomial convolution technique", contributes to provide self-extension with variable RNA length by treating RNA confined codons as mask filter for convolution applied with RNA key chain .The length of resultant key will be approximated to the summation of the length of mask filter and the length of RNA chain. It is worth mentioning, that mask filter has variable length according to confined codons number in RNA key chain, so the output of extended RNA-Crypto-key also has variable length with a high rate of randomness._This approach has two levels of RNA key extension, the first one comes from RNA codons table and the second one by applying Polynomial convolution technique. Algorithm (1) shows main steps of the proposal approach.

\begin{tabular}{l} 
Algorithm (1): Improved RNA-Crypto-Key \\
Input: \\
Initial key (characters, numbers),size $(9,12,15, \ldots$ etc/ byte) , No. \\
Iterations \\
Output: \\
Improving RNA random key with variable expanded size \\
\hline Begin \\
Step1 :Convert initial key sequence to binary sequence \\
Step2: Coding each 2 bit from the message binary sequence to \\
RNA 4base using table (1). \\
Step3: Split RNA strand into group of codons ( 3 nitrogenous \\
bases) \\
Step4: Extend each codon in RNA sequence by selecting another \\
codon that belong to the same amino acid and appending them, \\
according to table (II). \\
Step5: Read RNA strand until finding the AUG that is used to begin \\
protein synthesis, count the number codons and stop when finding \\
end codon is (UAA or UAG or UGA) \\
Step6: Extract Self-RNA-mask filter starting from AUG to (UAA \\
or UAG or UGA) \\
Step7: Apply rotate right shift on RNA strand based on the number \\
of confined codons-between start and end codon \\
Step8: Apply (Polynomial-Convolution) technique between Self- \\
RNA-mask filter and RNA strand based on equation (1) \\
final crypto-key \\
End
\end{tabular}

TABLE (1): CONVERT BIT SEQUENCE INTO MRNA NUCLEOTIDES

\begin{tabular}{|c|c|}
\hline Bit Sequence & mRNA Base \\
\hline 00 & $\mathrm{~A}$ \\
\hline 01 & $\mathrm{U}$ \\
\hline 10 & $\mathrm{C}$ \\
\hline 11 & $\mathrm{G}$ \\
\hline
\end{tabular}


TABle (2): CODING AMINo ACID Groups INTO BIT SEQUENCE

\begin{tabular}{|c|c|c|}
\hline Decienal cede & RVA code & Biary code based (6 Bif) \\
\hline 0 & UUU & 000600 \\
\hline 1 & UUC & 00061 \\
\hline 2 & UUA & 000010 \\
\hline 3 & UUG & 000011 \\
\hline 4 & CUU & 000100 \\
\hline 5 & CUC & 000101 \\
\hline 6 & CUA & 000110 \\
\hline 7 & cu6 & 000111 \\
\hline 8 & AUU & 001000 \\
\hline 9 & AUC & 01001 \\
\hline 10 & AUA & 001010 \\
\hline II & Rud & 001011 \\
\hline 12 & GUU & 001100 \\
\hline 13 & GUC & Q61101 \\
\hline 14 & GUA & 601110 \\
\hline 15 & GUG & OCIIII \\
\hline 16 & UCU & 010000 \\
\hline 17 & UCC & 010001 \\
\hline 18 & UCA & 010610 \\
\hline 19 & UCO & 010011 \\
\hline 20 & $C \mathrm{CU}$ & 010100 \\
\hline 21 & $\mathrm{CcC}$ & 010101 \\
\hline 22 & CCA & 010110 \\
\hline 23 & $\mathrm{CCO}$ & 010111 \\
\hline 24 & ACU & 011000 \\
\hline 8 & $A C C$ & 011001 \\
\hline 26 & ACA & 011010 \\
\hline 27 & $A C O$ & 011011 \\
\hline 23 & COU & 011100 \\
\hline 2 & $G C C$ & 011110 \\
\hline 30 & GCA & 011101 \\
\hline 3 & $\sigma C 6$ & 011111 \\
\hline 32 & UAU & 100600 \\
\hline 3 & UAC & 100601 \\
\hline 34 & IAA & 100010 \\
\hline is & wad & 100011 \\
\hline 36 & CAU & 100100 \\
\hline 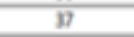 & CAC & 100101 \\
\hline 早 & CAA & 100110 \\
\hline 3 & $C_{A G}$ & 100111 \\
\hline 40 & MAU & 101000 \\
\hline 41 & $\triangle A C$ & 101001 \\
\hline 42 & MA & 101010 \\
\hline 4) & $A Q 6$ & 101011 \\
\hline 4 & GAU & 101100 \\
\hline 45 & $G A C$ & 101101 \\
\hline 45 & GAA & 101110 \\
\hline 47 & GAG & 101111 \\
\hline 44 & UGU & 110000 \\
\hline 49 & UOC & 110001 \\
\hline$\$$ & val & 110010 \\
\hline 51 & U60 & 110011 \\
\hline 52 & $\mathrm{cov}$ & 110100 \\
\hline 53 & $\operatorname{coc}$ & 110101 \\
\hline 54 & $\operatorname{CoA}$ & 110110 \\
\hline 58 & COC & 110111 \\
\hline s6 & $A G U$ & 111000 \\
\hline 57 & $A G C$ & 111001 \\
\hline 5 & $A O A$ & 111010 \\
\hline 49 & $A G G$ & 111011 \\
\hline 60 & 600 & 111100 \\
\hline 61 & $G G C$ & 111101 \\
\hline 62 & COA & 111110 \\
\hline 63 & 600 & 111111 \\
\hline
\end{tabular}

Note: Highlight green code on in Table (2) represents starts and Red represents end codons in mRNA strand

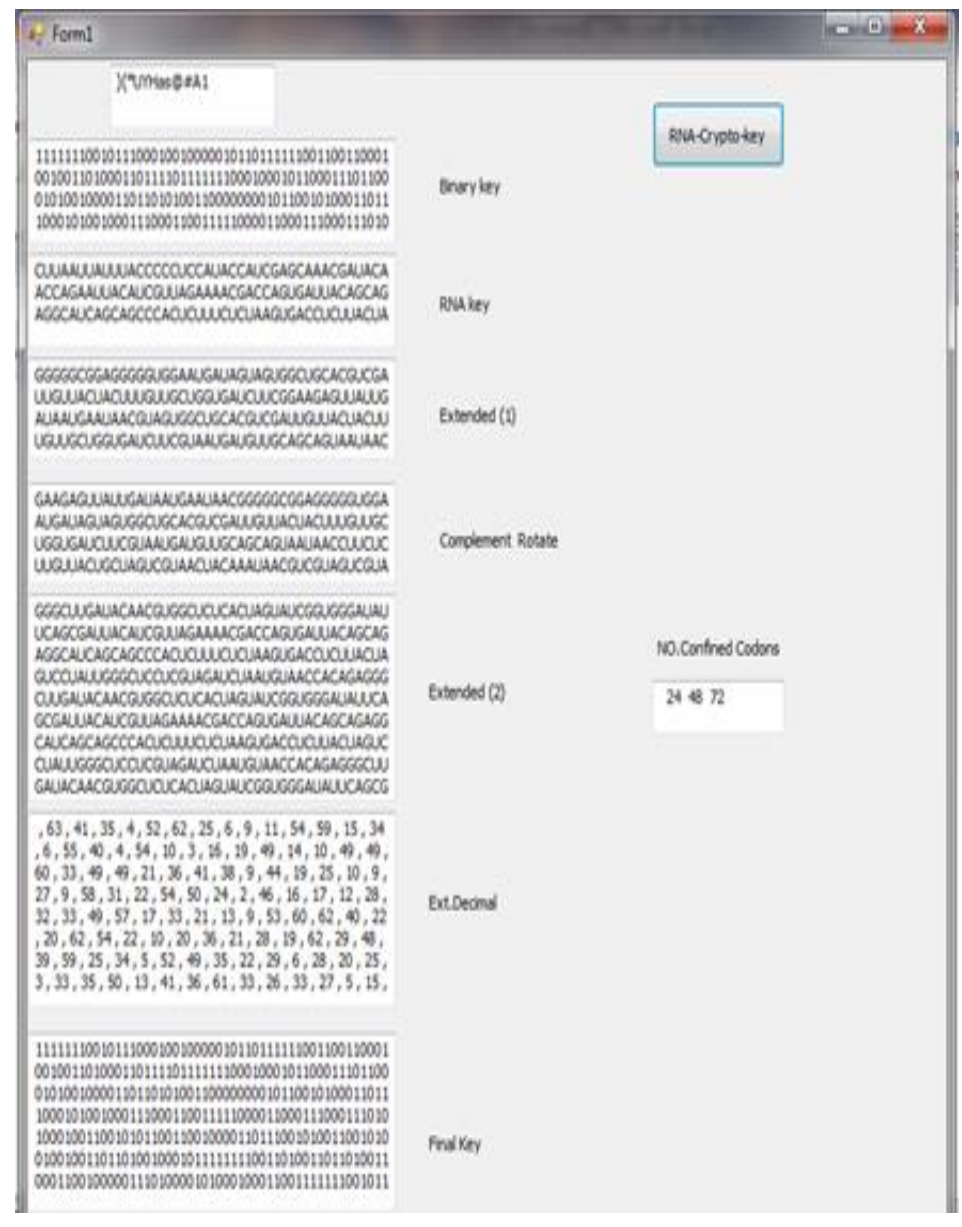

Fig. 1. Interface of proposed program using c\#.net

\section{EXPERIMENT A RESULT AND DISCUSSION}

This section illustrates the results that are obtained from the implementation of the proposed approach which is explained in the previous sections, these results can be presented as follows: Basic Statistical measurements of randomness have been done on the improved RNA as shown in Table (3). These statistical tests such as, frequency, serial, poker and runs are used to evaluate randomness and distributed properties of several RNA crypto- key samples [11]. Randomness tests were applied on various key sizes such as 9,_12 72,96 and 144_bits or bytes. Randomness is used to check random and distributed properties of several RNA crypto- key samples. Useful statistical tests are four basic tests, including: Frequency test, Serial test, Poker test, Runs test [10]. The output of tests must be compared with passes values to decide if the outputs of randomness tests are good or not. Randomness tests are applied on different key sizes: 72, 96 and 144_bits. 
Table (2): Coding Amino Acid Groups into bit Sequence

\begin{tabular}{|c|c|c|c|c|c|}
\hline $\begin{array}{l}\text { Initial } \\
\text { key size } \\
\text { (bit) }\end{array}$ & $\begin{array}{l}\text { Improved } \\
\text { RNA key } \\
\text { at } 3 \text { itr. } \\
\text { size(bit) }\end{array}$ & $\begin{array}{l}\text { Frequency } \\
\text { Pass <= } \\
3.84\end{array}$ & $\begin{array}{l}\text { Serial } \\
\text { Pass } \\
<= \\
5.99\end{array}$ & $\begin{array}{l}\text { Poker } \\
\text { Pass } \\
<=11.1\end{array}$ & $\begin{array}{l}\text { Run Pass } \\
<=22.362\end{array}$ \\
\hline \multirow{3}{*}{96} & 3324 & 0.123 & 0.544 & 7.321 & 5.161 \\
\hline & 2190 & 0.154 & 1.119 & 4.754 & 3.368 \\
\hline & 2388 & 0.342 & 3.182 & 10.407 & 15.164 \\
\hline \multirow{3}{*}{72} & 1758 & 2329 & 6.254 & 7.146 & 6.387 \\
\hline & 2088 & 3.065 & 3.571 & 8.321 & 18.462 \\
\hline & 1824 & 0.967 & 1.430 & 7.394 & 12.737 \\
\hline \multirow[t]{2}{*}{144} & 3306 & 0.756 & 2.49 & 10.89 & 8.406 \\
\hline & 3204 & 1.709 & 4.77 & 6.262 & 6.824 \\
\hline Average & & 1.18 & 2.92 & 7.81 & 10.21 \\
\hline
\end{tabular}

As shown in table (3), Improved RNA -key is achieved to high rate of randomness $(96 \%$ percentage of tests that is passed through statistics) when compared with previous method of RNA-key generation in table (4) that shows just Average of many tests. While Improved -key size is may be much larger than $40 \%$.

Table (4): Randomness Statistical Tests of Previous RNACRYPTO-KeY (BY AVERAGE)

\begin{tabular}{|c|c|c|c|c|c|}
\hline $\begin{array}{c}\text { Initial } \\
\text { Key }\end{array}$ & $\begin{array}{c}\text { Previous } \\
\text { RNA key } \\
\text { at 3 itr. } \\
\text { Size (bit) }\end{array}$ & $\begin{array}{c}\text { Frequency } \\
\text { Pass }<= \\
\mathbf{3 . 8 4}\end{array}$ & $\begin{array}{c}\text { Serial } \\
\text { Pass } \\
<=5.99\end{array}$ & $\begin{array}{c}\text { Poker } \\
\text { Pass } \\
<=\mathbf{1 1 . 1}\end{array}$ & $\begin{array}{c}\text { Run Pass } \\
<=\mathbf{2 2 . 3 6 2}\end{array}$ \\
\hline 96 & 1920 & 27.5 & 65.9 & 92.4 & 58.2 \\
\hline
\end{tabular}

Figure (2) illustrates Chart that shows the difference between the key expansion rates of the improved and traditional RNA key method through several iterations.

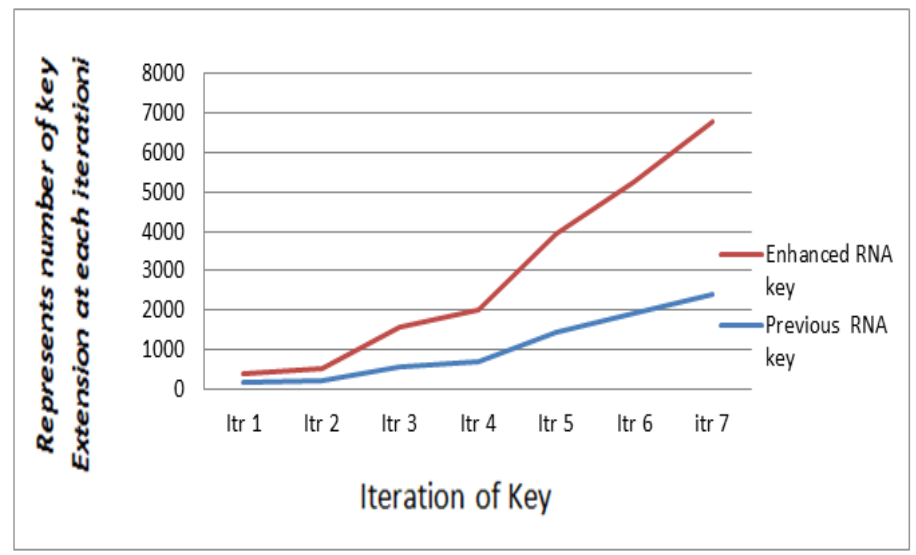

Fig. 2. Comparison in term of key expansion between traditional and proposed approaches

\section{CONCLUSION}

This paper describes an efficient method for Improving RNAcrypto-key generation using Polynomial Convolution. It successfully provides an extra level of extension and security for RNA-crypto-key when compared with the previous approach. . Robust features of this proposed method could be as follows:

- RNA-crypto-key expansion basically depends on several factors such as (start and end codons for translation, iteration numbers, and self-expansion based on codon table).

- Polynomial convolution provided more than $40 \%$ expansion on traditional RNA.

- Improved RNA-crypto-key provides_high rate of security randomness achieved $96 \%$ on other traditional RNA key generation method.

- $\quad$ Size of convolution mask filter may have a variable length based on start and end codon of each RNA strand and encoding of initial key.

\section{FUTURE WORK}

Improving -RNA algorithm considered as one of the optimization techniques which are used for solving any NPcomplete problem such as path planning, four colors mapping, TSP, CPU scheduling problems.

\section{APPENDIX(1)}

This section illustrates the implementation of the proposed approach which is programmed by using Visual c\#.net 2015 as shown in Fig (2). The following example explains in details steps of proposed algorithm work:

\section{- Initial key $(12$ byte $)=\quad)(* U Y H a s @ \# A 1$}

Step1. Binary coding (96 bits) $=$

(1111111001011100010010000010 $110 \quad 11111100110$ 0110001001001101000110111101111111000100010110001 $\begin{array}{lllll}110110001010010000110110 & 10100110 & 0 & 0 & 0\end{array}$ 000010110010100011011100010100100011100011001111100 001100011100011101010001001100101011001100100001101 110010100110010100100100110110100100010111111110011 010011011010011000110010000011101000010100010001100)

Step2. RNA Coding (48 nucleotide) = (CUUAAUUAUUUACCCCCUCCAUACCAUCGAGCAAAC GAUACAA CCAGA)

Step3. Extended (1) based on codon table $(96$ nucleotide $)=$ (GAAGAGUUAUUGAUAAUGAAUAACGGGGGCGG AGGGGGU GGA AUGAUAGUAGUGGCUGCACGUCGAUUGUUACUACUU UGUUGCUGGUGAUCUUCG)

Step4. Complement RNA \& Rotate= (GGGGGCGGAGGGGGUGGAAUGAUAGUAGUGGCUGC ACGUCGAUUGUUACUACUUUGUUGCUGGUGAUCUUC GGAAGAGUUAUUGAUAAUGAAUAAC) 
Step5. Extended (2) based on Polynomial Convolution (Note: mask filter length $\mathbf{2}$ 24)

(GGGCUUGAUACAACGUGGCUCUCACUAGUAUCGGUG GGAUAUUCAGCGAUUACAUCGUUAGAAAACGACCAG UGAUUACAGCAGAGGCAUCAGCAGCCCACUCUUUCU CUAAGUGACCUCUUACUAGUCCUAUUGGGCUCCUCG UAGAUCUAAUGUAACCACAGA)

Step6. Random Key Generation $(330$ bit $)=$ (111111100101110001001000001011011111100110011000100 100110100011011110111111100010001011000111011000101 001000011011010100110000000010110010100011011100010 100100011100011001111100001100011100011101010001001 100101011001100100001101110010100110010100100100110 11010010001011111110011010011011010011000110010000 $011101000010100010001100)$

\section{REFERENCES}

[1] Estabraq Abdulredaa," Number Generator Improvement based on Artificial Intelligence and Non Parametric Statistic_Methods", ISSN: 2454-9916, Volume: 1,_Dec 2015. Available on: http://ierj.in/journal/index.php/ierj/article/view/62

[2] W. Stallings, "Cryptography and Network Security Principles and Practices", third addition, Pearson Education, Inc, 2003.Available on:http://faculty.mu.edu.sa/public/uploads/1360993259.0858Crypto graphy $\% 20$ and $\% 20$ Network $\% 20$ Security $\% 20$ Principles $\% 20$ and $\% 2$ OPractice, $\% 205$ th $\% 20$ Edition.pdf

[3] Andrea Rỡck "Pseudorandom Number Generators for Cryptographic Applications" ,Ph.D. thesis , der Paris-LodronUniversity Salzburg,2005.Available on: https://www.rocq.inria.fr/secret/Andrea.Roeck/pdfs/dipl.pdf

[4] Ashish Gehani, Thomas LaBean, John Reif, "DNA-Based Cryptography”, Volume 54, ,Department of Computer Science, Duke University 2000.Available on: http://www.csl.sri.com/users/gehani/papers/DIMACS1999 .DNACr ypto.pdf

[5] Alia Karim,_. "Proposed Approach for Key Generation Based on the $R N A$ http://www.iasj.net/iasj?func=fulltext\&aId=102167.

[6] P. Akkara, "Applying DNA Self-assembly in Formal Language Theory", MSc, University of Cincinnati, Engineering and Applied Science: Computer Engineering,_2013.

[7] L._Accardi, W. Freudenberg M._Ohya, "Quantum Bio-informatics II", Tokyo University of Science", Japan,_March 2008.

[8] P. J. Diggle, "A kernel method for smoothing point process data", Journal of the Royal Statistical Society, Series C 34: 138-147, 2011.

[9] Frank Keller,_ “Computational Foundations of Cognitive Science”, School of Informatics University of Edinburgh, February, 2010. Available on : http://www.inf.ed.ac.uk/teaching /courses/ cfcs1/ lectures/ cfcsl15.pdf

[10]E. Barker, A. Roginsky, ' Recommendation for Cryptographic Key Generation ', National Institute of Standards and Technology Special Publication, December- 2012._Available on:

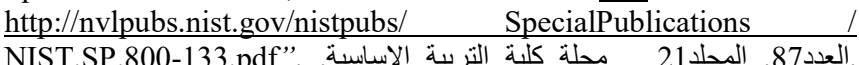
2015.Available on: munications security. ACM, 2002, pp. 41-47. 